\title{
La ironía en El Demonio de los Andes
}

\author{
Por Wilfredo Kapsoli Escudero
}


Doctor en Historia por la Universidad Nacional Mayor de San Marcos. Estudio de Postgrado en la Escuela Práctica de Altos Estudios de París. 


\section{Introducción}

La risa del "Demonio de los Andes" forma parte de un proyecto desde una perspectiva histórica. Está personificada en la figura del conquistador Don Francisco de Carbajal. La documentación básica que lo refrenda es la semblanza biográfica realizada por Ricardo Palma en un folleto titulado EL DEMONIO DE LOS ANDES e ilustrada con doce tradiciones.

La Historia empieza con la biografía del personaje donde está presente las referencias familiares al pueblo de origen y a las batallas triunfales antes de su llegada al Perú. Luego se relata su vinculación con las huestes de los Pizarro (Francisco y Gonzalo) quienes vivían una coyuntura de crisis, de guerras civiles entre los conquistadores, que culminó con la "Gran Rebelión" de 1544-1548. En esta parte podemos observar el énfasis que pone en los rasgos psicológicos y morales de su biografiado. La ironía y la fidelidad, en una época de odio, de traición y de muerte, era absolutamente inimaginable: encontrar a un hombre como Francisco de Carbajal que se burlaba de la vida peor que de la lealtad y de la palabra empeñada. Estos valores debieron ser decisivos para que Don Ricardo Palma lo encumbrara en este singular documento.

Las 12 tradiciones que siguen ilustran lo anterior jocosamente, de un hombre tenebroso pero por momentos hilarante. Es un degollador innato. Tiene en su haber más de 300 decapitados y un sinnúmero de flagelados y prisioneros. No entra en 
miramientos ni medias tintas. Actúa por instinto y con mucho olfato político. De este modo, se ha hecho de una fama por la que se le teme y obedece. Pero, es un hombre fiel que "besa las manos de su amo como humilde servidor", y no tiene empacho en reírse del dolor ajeno. Así lo hace en "Comida acabada, amistad deshecha", "Sueños de un santo varón”, "Los postres del festín", etc.

La lectura de El Demonio... nos permite puntualizar la sutil identificación del autor con el proyecto independentista de Gonzalo Pizarro a quien considera como "el muy magnífico". Elogia sus acciones y anota: "Estaba escrito que no era Pizarro el escogido por Dios para crear la nacionalidad peruana”. Gonzalo el iluso y su fiel Francisco actúan al alimón en escenas y diálogos que nos remiten al fascinante mundo del Quijote y Sancho. Así lo habría imaginado el autor para darles vida propia aunque, en este caso, invirtiendo la figura del protagonismo: el escudero ocupa el primer plano de la obra.

\section{El personaje}

Conocemos dos semblanzas de Francisco de Carbajal, ambas preparadas para Diccionarios Histórico - Biográficos por Manuel de Mendiburu y José Antonio del Busto. La primera de 1932 y la segunda de 1986. Mendiburu, al final de su texto, recomienda "consultar también la obra de don Ricardo Palma, titulada El Demonio de los Andes. Ed. Nueva York, 1883”. Del Busto ha trabajado, más bien, con documentos del Archivo General de Indias de Sevilla y del testimonio de los cronistas. Compaginadas ambas lecturas, sobre todo con la correspondencia de Francisco de Carbajal, queremos puntualizar algunos rasgos que tienen que ver con la psicohistoria, la moral y la risa que acompañaron a nuestro héroe en la coyuntura de la "Gran Rebelión". 
Nació en Rábana de Arévalo y fue bautizado con el nombre de Francisco López Gascón. Fue enviado a estudiar a Salamanca. Allí, lejos de cumplir su cometido se dedicó a la diversión y al derroche. Abandonado por su familia viajó a Italia donde sirvió al Cardenal Bernardino de Carbajal del que tomó su apellido. Guerreó en las batallas de Ravena (1512) y de Pavía (1525) y participó en el saqueo de Roma (1527) apoderándose de un archivo notarial por el que pidió mil ducados de rescate "oyendo los ruegos de su afligido dueño". Posteriormente vino a México con la viuda Catalina Leyton con quien contrajo matrimonio. En 1536 es requerido por Francisco Pizarro para sofocar el levantamiento de indios y romper el cerco de Lima. Fue nombrado Alcalde del Cuzco en 1541 y beneficiario de indios de repartimiento. Hombre de armas, de ingenio militar y, sobre todo de humor. Su vida pendía con el hilo de la muerte. Se salvó de varios intentos de asesinato $y$, en ocasiones, fue herido por sus propios seguidores. Es que era temido y odiado a la vez. Su ferocidad y ensañamiento fueron aplacados pocas veces con el poder del dinero y de la lisonja.

Juan Pérez de Tudela presenta a Carbajal en el banco de los extremistas que apoyan a Gonzalo Pizarro frente a otros moderados como el Arzobispo Loayza. Literalmente dice:

De los que puso en juego Pizarro, el más contundente, sin disputa se llamó Francisco de Carbajal, el celebérrimo "maestro de campo"; un viejo desalmado con trasnochados ribetes de cultura clerical, excelente táctico de la arcabucería y mejor táctico de la flaqueza del corazón humano; que se sintió grande y talentoso prodigando una crueldad absolutamente pragmática, puesto que no era la aflicción del prójimo lo que en verdad perseguía, sino implantar terrores y calmar una sed codiciosa sin posible hartura.

Pero, mejor veamos a nuestro personaje con sus propias palabras. La correspondencia que sostuvo con su "Rey Gonzalo" y otros 
"Magníficos Señores" nos permite su autorretrato moral y psicológico.

La primera, fechada en Lima el 25 de Octubre de 1545, está dirigida a Gonzalo y allí se lee, entre otras cosas: “... allegamos a esta ciudad de los Reyes, a donde fuimos muy solemnemente rescebidos como criados de vuestra señoría(...) todos han mostrado el deseo que tienen de servir a vuestra señoría en el buen tratamiento que nos han hecho, porque en mi conciencia que otra cosa no ha faltado sino meternos en sus entrañas". Luego sigue una retahíla de recomendaciones que solicita como "testigo de vista":

1. Al muy principal capitán Lorenzo de Aldana que se "ha gobernado como buen caballero y tanta buena gracia y valor, que derramado muchos nublados. No ha perdonado con toda su prudencia algunos rigores y en tal tiempo y tan sabiamente lo ha hecho todo".

2. A Don Antonio de Rivera que "no sería honesto que se quedase en el tintero, ni la señora doña Inés, pues sus servicios son tan notorios pagando y sosteniendo gentes en su casa para que sirviesen a vuestra señoría".

3. A la señora doña Francisca que "está muy buena y muy hermosa y muy grande... paréceme que es tiempo que vuestra señoría la mande casar".

4. Al padre Diego Martín que entiende las cosas del Estado tan valerosamente. Hartos duelos tendríamos si no fuese por él y "a ver si vuestra señoría no le hace obispo o arzobispo de alguna gran prelacía con toda la brevedad posible". 
5. A Pedro López, "hombre hecho y valiente". Sirve a vuestra señoría con mucha afición "predicando a maliciosos y gasta también lo que tiene con nuestros amigos".

6. Al Licenciado de La Gama que "trajo el oro del Rey que estaba en el Cuzco. Es tan aficionado servidor de vuestra señoría que no sé cómo lo pudiese significar, porque no lo sé escribir ni decir a bica tan bien como yo lo entiendo. A vuestra señoría suplico tenga mucha memoria de él...”.

7. A Antonio de Robles, Alguacil Mayor de esta ciudad quien, además de hacer su oficio tan derechamente, sirve a vuestra señoría con su persona y hacienda. Él se ha ofrecido al sacrificio tan prolijo de ir camino a Usted con estos despachos con la afición que tiene de servirle y verle la cara. Para esto debe haber pensado lo que suelen decir:

"Hombre que tu gesto vea, jamás puede ser perdido honesto".

Carbajal abunda en razones para reiterar sus consideraciones a favor de su patrocinado:

"Primero es servidor de vuestra señoría; segundo es hermano del capitán Martin de Robles; tercero es hidalgo; cuarto es casado; quinto que si vuestra señoría puede vivir sin él, él no puede vivir sin vuestra señoría ni sus mercedes; sexto, que si algunas faltas hubiese en nosotros, las ha de suplir vuestra señoría como buen señor y ésta es la verdadera y más principal".

8. Y como preámbulo al siguiente aval, el Demonio se confiesa:

"siempre me suele a mí acontecer que lo más encomendado me lleve el gato y que en la mejor senda se me olvide de poner cuerda" que el alcalde Pedro Martín "ha sido tanta parte para la quietud y 
sosiego de esta tierra que vuestra señoría ha sido muy servido de él" que vive en mucha pobreza, y debe tener mercedes.

9. Que don Antonio de Rivera, El Viejo, sea Alcalde de Lima paréceme conviene a vuestra señoría porque

... de la misma manera lo rodeó el Marqués de gloriosa memoria, que en gloria sea (se refiere a Francisco Pizarro) para que yo sea Alcalde en el Cuzco en el año de cuarenta y después el año de cuarenta y uno, no embargante de las leyes del reino que hablan en contrario de esto, porque algún rato para lo que conviene bien pueden descansar las leyes. Y pues en España no se pueden traer mulas de sillas ni vestir brocados y cosas y aquellas premáticas no se guardan acá, también se pueden derogar por algo rato la ley del reino que digo.

10. La mujer e hijo del capitán Blas de Soto, que murió en el Cuzco sirviendo a vuestra señoría, sean aprovechados del repartimiento de indios y "no participen de bien ninguno lo viejos malvados, a lo menos el padre, porque querría vernos hecho pedazos".

11. El capitán Valdivia "es muy amigo y conozco que es hombre de bien y persona humilde y bien conocido pero, crea vuestra señoría que, con todas estas buenas costumbres, cuando ya está en aire de gobernador, siempre querrá ser gobernador antes que lo sea San Pedro de Roma, y ansi por eso, como por lo que podría venir por el estrecho, es bien que vuestra señoría mire sobre lo que en esto de Chile se hubiere de proveer, porque es un negocio muy hondo".

12. Pedro Díaz que, estos despachos lleva en su nave, "mucha pólvora para la armada y veinte quintales de bizcocho", sea también merecedor de atenciones. 
La comunicación termina con una recomendación y una larga lisonja:

Vuestra Señoría mire mucho por la armada y por su salud, que estas dos cosas nos tengan en pie de aquí a mil años, a pesar de reyes y aun de papas.

Las tres cartas que siguen fueron enviadas desde Chuquisaca, entre octubre y diciembre de 1546. En ellas Carbajal muestra su otra faceta, la del pecador mortal, la de no hacer bien a nadie. Veamos sus ejemplificaciones:

1. Empezamos a poner orden en el Cabildo para que "las gentes entiendan la mejoría que les venía de la venida del exército de vuestra señoría”; por entonces, el 28 de setiembre "víspera del glorioso Arcángel San Miguel tenían concertado en esta villa hasta quince o veinte traidores de matarme a mí y a otros caballeros de estos capitanes y más favorecidos hidalgos de vuestra señoría”. Los inventores de esto eran los de Centeno y algunos otros como Luis Perdomo, Diego Balmaceda, Antonio Luján, Juan Ramón, Alonso Díaz de Gibraltar y un tal Matías de Morales. De estos logramos tomar presos a algunos de ellos y, al siguiente día:

“... de El Señor de San Miguel hicieron cuartos en la plaza de esta villa a Alonso Camargo y Diego de Balmaceda $y$, se pusieron en estos caminos donde al presente están mostrando el camino a los que pasan" (Nótese la forma irónica de su comunicación).

A los demás, que huyeron pero que se los trajo presos Castillo, Espinoza, Argüello y Juan Vélez- se les hizo igualmente cuartos. Luis Perdomo solo y desnudo escapó por las yungas y no hay duda de que lo han matado los indios. Y, con todo sarcasmo, Carbajal se complacía: 
“... escríbole a vuestra señoría para que entienda cuan meritoria cosa debe ser para con Dios hacer bien a estas benditas personas; por tan descomedidos e ingratos..."

2. Sobre lo anterior, escribe también a Pedro de Soria:

“... y como el diablo nunca duerme, hago saber a vuestra merced que andamos en rastro de Luis Perdomo y el señor Castillo. Vuestra merced ruegue a Dios que lo tomemos, porque no anden los cuitados perdidos que quebrada en quebrada".

3. Carbajal se autocalifica de "muy malo pero servidor sin pesadumbres”. Y señala que “... hay personas que si de mañana hacen los servicios, quieren estar pagados de ellos cuando a vísperas tengan y, en mi lenguaje llamo yo a esto: "fiar a Dios sobre buena prenda"; amohinarme en tanta manera que quiero más que lleven los diablos que no ver semejantes cosas y no ser parte para remediarlas, ...". Por eso está incómodo con el destierro a Chile del traidor Blasco Sánchez de Ulloa: “... pareció el corazón de aquel juez muy amoroso y blando”. En tal persona, el destierro es no reconocerle su culpa. “... ya veré si está bien o sino lo desterraré más lexos”, dice Carbajal, con clara alusión al "más allá", esto es, a la muerte.

4. Lope de Tobalina, vizcaíno, es uno de los diez traidores que se me huyeron en Hayo-Hayo (Abancay) a quien hice prender en la picota y "lo hicieron cuartos en el Cuzco". Vea vuestra señoría el fin que hacen estos traidores.

5. De Arequipa escribe a Gonzalo Pizarro el 25 de agosto de 1547.

“... vuestra señoría crea que esta ciudad es generalmente traidora toda, que no hay pared en ella que no sea traidora y traidor el río y traidor el sol que la alumbra y el aire que la sostiene" 
6. Su predilección por la muerte de sus enemigos lo hace saber al mismo Licenciado Pedro de la Gasca:

"Tan maravillado estoy con vuestros desatinos... que basta la burla un rato y no hagáis irregularidades a los otros. Y esto le digo por un mensajero que hicisteis enviar a un bellaco de un clérigo y otros mensajeros porque en llegando yo los hice ahorcar y van sobre la pecadorcita de vuestra animita".

Sobre aquel texto, Gasca habría hecho la siguiente glosa marginal:

"Es tan odioso a Gonzalo Pizarro y los de su rebelión, que su gente sepa la misericordia que Su Majestad ha sido de muerto don Francisco de Carbajal, historiado por la fecunda pluma Palmista".

\section{El texto}

1. Hemos microfilmado la edición de 1883 (Sala de Investigaciones de la Biblioteca Nacional) y trabajando con él podemos señalar que es un folleto de 81 páginas de formato pequeño de 10 por 15 centímetros y el ejemplar está dedicado a puño y letra al Señor Manuel Pablo Olaechea. Se compone de dos partes claramente diferenciadas: por un lado, la biografía del conquistador don Francisco de Carbajal y por otro las 12 tradiciones que lo secundan. La primera, es una sucinta presentación del personaje. Empieza con referencias a los familiares, al pueblo de origen, a las batallas triunfales en Italia y a su posterior traslado al Perú. aquí relata su vinculación con las huestes de los Pizarro (Francisco y Gonzalo) quienes vivían una coyuntura de crisis, de guerras civiles entre los conquistadores que culminó con "La Gran Rebelión de 1544-1548. En esta parte podemos observar el énfasis que pone en los rasgos psicológicos y morales de su biografiado: la ironía y la fidelidad. En una época de odio, 
de traición y de muerte era absolutamente inimaginable encontrar a un hombre como Francisco de Carbajal que se burlaba de la vida peor no de la lealtad y de la palabra empeñada. Estos valores debieron ser decisivos para que don Ricardo Palma lo encumbrara en este singular documento".

Las 12 Tradiciones que siguen ilustran lo anterior jocosamente. En ellas aparece El Demonio con su típico protagonismo de hombre tenebroso pero, por momentos, hilarante. Es un degollador innato. Tiene en su haber más de 300 decapitados y un sinnúmero de flagelados y prisioneros. No entra en miramientos ni medias tintas. Actúa por instinto y con mucho olfato político.

De este modo se ha hecho de una fama por la que se le teme y obedece. Pero, es un hombre fiel que "besa las manos de su amo como humilde servidor" y no tiene empacho de reírse del dolor ajeno. Así lo hace en las ya citadas "Comida acabada, amistad deshecha", "Sueños de un santo varón", "Los postres del festín", etc.

La lectura de la primera edición de El Demonio nos permite puntualizar la sutil identificación del autor con el proyecto independentista de Gonzalo Pizarro a quien le considera como "el muy magnífico". Elogia sus acciones y anota: "Estaba escrito que no era Pizarro el escogido por Dios para crear la nacionalidad peruana". Gonzalo el iluso y su fiel Francisco actúan al alimón con escenas y diálogos que nos remiten al fascinante mundo del Quijote y Sancho. tal como se ha dicho. Así lo habría imaginado el autor para darles vida propia aunque, en este caso, invirtiendo la figura del protagonismo: el escudero ocupa el primer plano de la obra. 


\section{LA BIOGRAFÍA DE LAS TRADICIONES}

\begin{tabular}{|l|c|c|c|}
\hline Títulos & Números & Años & Ediciones $\left(^{*}\right)$ \\
\hline Noticias históricas sobre Carbajal & 36 & 1872 & $\ldots$ \\
\hline 1. Los tres motivos del oidor. & 142 & 1879,1883 & RP. D.VI \\
\hline 2. El que se ahogó en poca agua. & 102 & 1877,1883 & IV.D.VI \\
\hline 3. Si te dieron hogaza no pidas torta & 100 & 1877,1883 & RP.D.VI \\
\hline 4. Comida acabada, amistad terminada & 171 & 1879,1883 & RP.D.VI \\
\hline 5. El sueño de un santo varón & 148 & 1879,1883 & RP.D.VI \\
\hline 6. Los postres del festín & 155 & 1879,1883 & RP.D.VI \\
\hline 7. Los hechos y por hacer & 180 & 1883 & D.VI \\
\hline 8. Maldición de mujer & 181 & 1883 & D.VI \\
\hline 9. Un hombre inmortal & 182 & 1883 & D.VI \\
\hline 10. iAy cuitada! Y guay de lo que & 183 & 1879,1883 & D.VI \\
\hline \multicolumn{1}{|c|}{ aquí andaba } & & & RP.D.VI \\
\hline 11. La bofetada póstuma & 141 & 1877,1883 & IV.D.VI \\
\hline
\end{tabular}

Fuente: Elaborado en base a "En torno a Ricardo Palma" de Guillermo Feliú Cruz y "La lista cronológica de las Tradiciones" de Merlín Comptom.

(*) Clave de los Símbolos:

RP - Revista Peruana. D. - Demonio... VI - Tercer volumen de las Tradiciones, Barcelona, 1984.

La anatomía del primer Demonio (que observamos en el cuadro anterior) nos permite ubicar cuatro momentos cronológicos: 1872, 1877(3), 1879(5) y 1883(4). El primero corresponde al Personaje y los tres restantes a las Tradiciones. En el conjunto de la producción intelectual de Ricardo Palma estos años corresponden a lo que Raúl Porras ha calificado "la época eufórica de su creación" y que el historiador la ubica entre 1870 - 1890. Su intensa preocupación por el género histórico-literario lo definió él mismo: 
“La Tradición no es precisamente historia, sino relato popular y ya se sabe que para mentiroso el pueblo...

Yo no invento; copio. Soy un pintor que restaura y da colorido a cuadro del pasado"

Historia sonriente ,"con el arte de narrar el cuento y la tradición oral del pueblo, o enlazada con el amarillento infolio o sea la fusión feliz de lo popular y lo erudito, he ahí el afortunado e inaprensible secreto de las Tradiciones" dice Raúl Porras en el prólogo al Epistolario de Palma.

En un comentario posterior (prólogo a una selección de Tradiciones), Porras piensa que esta entrega al pasado, con su rancio olor a los manuscritos y a los archivos, habría frenado su desbordada, creatividad humorística:

La obsesión historicista alejó

a Palma de la espontánea desenvoltura

de los escritores propiamente satíricos.

Pero reconoce, con toda precisión, la capacidad burlesca y la vena volteriana del tradicionista:

Palma animó con su propio espíritu e imaginación muchos de los personajes históricos que vivían escueta y secamente en las crónicas y documentos notariales. Él les ha prestado vida y carácter a personajes que hoy día emanan en la memoria popular, como en las figuras ya divulgadas y carentes de fuerza expresiva antes de él, tales El Demonio de los Andes, la Monja Alférez, el Virrey Poeta, Fray Martín de Porres, Amat y la Perricholi, etc.... 
Con todo, Porras vuelve a su afirmación inicial. Se lamenta que Palma no haya hecho una novela con los personajes de su tiempo que andaban sueltos por las calles de Lima como Manongo Moñón o bófeta del diablo, Tadeo López, Bernardito o Ño Cerezo, Ño Bracamonte tocador de Arpa, etc. Estos hubieran tenido "por obra de la imaginación del artista y no a mérito de andaderas y zancos documentales, una realidad más profunda y duradera que la de los personajes históricos". En suma, Palma dejó los caminos que lo hubieran podido llevar a la creación de una gran novela peruana, con sus personajes arquetípicos nutridos por la sabia popular, pero prefirió hacer la epopeya histórico-cómica del Perú:

Cuando Palma teje la urdimbre del relato, ya sea en la figura del héroe histórico o del personaje novelesco, no lo instala en la noria o lo empuja al circunloquio. Lo sitúa en su hábitat y lo invita a evadirse de él. La Tradición, es de este modo, una constante fuga, una concesión al otro, una habilidad del transformista. La historia se presume, en cambio, un incontrovertible testimonio, un hecho consumado.

Aparte de la información oral y de su experiencia vital Palma recurrió al manejo de otras fuentes para recrear sus personajes. Alberto Tauro ha documentado algunas de las Tradiciones como: "Los tres motivos del Oidor" hecho a partir de Diego Fernández en su Historia del Perú (Libro I, caps. XXV y XXXIV; y Libro II, cap. XLVIII), "Las hechas y por hacer" preparado en base a Los Comentarios Reales de Garcilaso de la Vega (II parte, libro V, cap. XLI), "Ay cuitada y guay de lo que aquí andaba” se elaboró tomando como referencia los Quincenarios o Historia de las Guerras Civiles del Perú (Libro III, Cap. XXXIV) de Pedro Gutiérrez de Santa Clara. Tauro presenta varios casos más y dentro de ellos tres que forman parte de I corpus de nuestro Demonio... 
En la cronología de las Tradiciones se nota que 1872-1873 son los años de la construcción de las semblanzas históricas de los Conquistadores, como Francisco de Carbajal, Hernando de Soto, Diego Centeno, Pedro de Candia, Martín de Robles y Lope de Aguirre, entre otros. De estos, Lope de Aguirre fue elegido para una novela: "Los Marañones" que el autor habría terminado de elaborarla. Lamentablemente los originales desaparecieron durante el incendio de Miraflores por las fuerzas de ocupación chilena, en 1881. Lope de Aguirre, con el epíteto de "El Traidor", fue incorporado a la segunda edición de El Demonio... Los períodos siguientes de 1877 y 1879 son años de intensa creación con temas fundamentalmente coloniales. Y el último de 1883 está dedicado a El Demonio de los Andes. Eran los años de la Campaña de la Breña, de la resistencia cacerista contra la invasión chilena. Ricardo Palma, con su patriotismo puesto a prueba, fue corresponsal de guerra con el seudónimo de "Sirius". No sería raro que las hazañas de los campesinos liderados por Andrés Avelino Cáceres, "El Brujo de los Andes", lo hayan alentado a escribir sobre su virtual epónimo don Francisco de Carbajal, más conocido como "El Demonio de los Andes".

La segunda Edición de El Demonio... de 1911 fue hecha en Barcelona bajo el sello editorial de Maucci. Está dedicada a Ricardo Becerra en Colombia, de formato igualmente pequeño como el anterior. Esta entrega fue ilustrada aunque sin el crédito específico y lleva la fotografía del autor que no corresponde a su momento sino, más bien, a una de varios años antes (1983). A la anatomía de El Demonio... de 1883, Palma incorpora cuatro tradiciones más. Dos que corresponden al ciclo original de 1872-1873 ("A iglesia me llamo" y "Lope de Aguirre, el traidor") y los dos restantes: "La malaventura del secretario de Carbajal" y "El hijo de la dicha" son de 1888 y 1891 respectivamente. Estos corresponden al ciclo donde el protagonismo recae en la 
figura del pacificador Pedro de la Gasca (véase: "Motín contra la Gasca" "Niñería de Niño" y "Los que están a la Mira"). A parte de estos cambios, los textos de la primera edición; sufrieron modificaciones sustanciales para la segunda que anotamos en esta Tercera edición crítica.

¿Qué pasó con El Demonio de 1883 al reaparecer en 1911? ¿Nueva York y Barcelona crean Demonios diferentes; actúan solos en un lado y con compañías que le hacen sombra en el otro? Estas preguntas trataremos de responderlas interrogando a su propio creador, es decir, al mismo Ricardo Palma.

\section{Bibliografía}

Ricardo Palma. El Demonio de los Andes. Ediciones: a) Nueva York 1883, b) Madrid, 1911. 